symptoms. Results to 3-month follow-up. British Journal of Psychiatry, 182, 303-311.

Johnstone, E. C., Frith, C. D., Crow, T. J., et al (1992) The Northwick Park 'Functional' Psychosis Study: diagnosis and outcome. Psychological Medicine, 22 $331-346$

Pilling, S., Bebbington, P., Kuipers, E., et al (2002) Psychological treatments in schizophrenia: I. Metaanalysis of family intervention and cognitive behaviour therapy. Psychological Medicine, 32, 763-782.

Turkington, D. \& McKenna, P. (2003) Is cognitivebehavioural therapy a worthwhile treatment for psychosis? British Journal of Psychiatry, 182, 477-479.

K. Marlowe South London and Maudsley NHS Trust, Lambeth Early Onset Services, 3-6 Beale House, Lingham Street, London SW9 9HG, UK

\section{NICE guidelines and maintenance ECT}

The recently released National Institute for Clinical Excellence (NICE) guidelines on the use of electroconvulsive therapy (ECT) discourage the use of maintenance ECT in depressive illness, the reasons being that: '.. the longer-term benefits and risks of ECT have not been clearly established ...' (NICE, 2003).

The only result of this will be to limit the patients' right to choose their treatment. The few patients who are considered for maintenance ECT live in the community and, therefore, are not subject to the Mental Health Act 1983. They will receive ECT because they want to and will have at any time the right to withdraw from it. These patients will have already tried, unfortunately without success, any other possible maintenance treatment and tend to respond only to ECT during their frequent acute episodes. Because of these experiences they know very well the pros and cons of ECT in their individual cases.

These are patients who, knowing their illness and the effects of ECT, have reached the conclusion that they prefer to receive ECT on a monthly basis rather than having to accept a life sentence of constant and frequent relapses of their depressive illness. If the maintenance ECT works and keeps them functioning in the community, it is my experience that they will be happy to continue with it for a long time. If it does not work, after a few attempts they will stop, encouraged by their psychiatrist.

Every patient is different and we still know very little about depression. The only result of the application of the NICE guidelines on maintenance ECT will be to deprive informed and intelligent patients of the freedom to choose a treatment that, if used appropriately, can make the difference between a life of misery and a relatively normal existence (Andrade \& Kurinji, 2002).

Andrade, C. \& Kurinji, S. (2002) Continuation and maintenance ECT: a review of recent research. Journal of $E C T, \mathbf{1 8}, 149-158$.

National Institute for Clinical Excellence (2003) Guidance in the Use of Electroconvulsive Therapy (Technology Appraisal Guidance 59). London: NICE.

M. Procopio The Priory Clinic, Hove, 14-18 New Church Road, Hove BN3 4FH, UK

\section{Flashbacks and PTSD in US veterans}

We read with interest the article by Jones et al (2003), who reported an absence of flashbacks in the symptom reports of exservicemen from the Second World War awarded pensions for post-combat disorders. As acknowledged by the authors, a limitation of the study is the retrospective review of historical descriptions of postcombat disorder symptoms in their sample population.

We administered the Clinician Administered Posttraumatic Stress Disorder Scale (CAPS) (see Weathers, 2001) to 82 American combat veterans of the Second World War who had also been held as prisoners of war (POWs). These veterans were seen as part of a compensation and pension examination conducted by the US Veterans Administration to examine the overall health status and presence of serviceconnected disabilities in these highly stressed veterans. CAPS interview question B-3 specifically asks the frequency (range: $0=$ none to $4=$ daily) and intensity (range: $0=$ none to $4=$ extreme) of flashback phenomena. Six of 41 ex-POWs (14.6\%) who met criteria for post-traumatic stress disorder (PTSD) reported flashbacks in the month prior to the CAPS interview at a combined frequency and intensity score of 4 or greater. None of 41 ex-POWs who did not meet criteria for PTSD reported flashbacks at this level of frequency and intensity. In contrast, 75 of 124 Vietnamera veterans $(60 \%)$ who had been diagnosed with combat-related PTSD and were administered the CAPS while participating in a Veterans Administration PTSD treatment programme reported flashbacks at this level of severity.
Consistent with the report of Jones et al, we found a striking difference in the prevalence of flashback symptom severity across generational cohorts. However, with specific questioning about this symptom using the standard diagnostic instrument for PTSD, the Second World War cohort who suffered extreme stress and currently meet criteria for PTSD did report flashbacks. The six former POW subjects who reported a current clinically significant level of flashbacks have informed us that this phenomenon was present in the 1940s. Of course, we cannot know whether these subjects would have reported flashbacks in the 1940s without having been exposed to the interim cultural changes.

Jones, E., Vermaas, R. H., McCartney, H., et al (2003) Flashbacks and post-traumatic stress disorder: the genesis of a 20th-century diagnosis. British Journal of Psychiatry, 182, 158-163.

Weathers, F., Keane, T. \& Davidson, J. R. (200I) Clinician-administered PTSD scale: a review of the first 10 years of research. Depression Anxiety, 13, 132-156.

T. Kimbrell, M. Myers, T. Freeman North Little Rock PTSD Program, North Little Rock VAMC, Mail Code: II6AP/NLR, 2200 Fort Roots Dr., North Little Rock, AR 72114, USA

\section{Counselling and psychotherapy: media distortion}

As the authors of the Cochrane Collaboration review on 'psychological debriefing' (Rose et al, 2002) following exposure to a traumatic experience, we were concerned to see our research taken out of context during the recent media debate on counselling and psychotherapy. Our research related to the lack of evidence supporting a 'one-off' intervention following trauma. Even its proponents would not regard this intervention as counselling or psychotherapy. Yet journalists have cited this research as new and generalised its findings to the extent of proclaiming that all counselling and psychotherapy is not useless but dangerous. This is unjustified.

The research is not new. We first published this as a systematic review in 1998 (Rose \& Bisson, 1998) and it continues to be updated in the normal way. The generalisation of our findings is scientifically unacceptable and, more importantly, potentially harmful. It is clear that counselling and psychotherapy are not beneficial to everyone. However, there is good evidence that many psychological treatment approaches are effective, including multiple-session early 